\title{
Knowledge Management in Brazil: What Governance Mechanisms are Needed to Boost Innovation?
}

\section{Guillermo Antonio Dávila, ${ }^{1} \odot$ Tatiana Andreeva, ${ }^{2} \odot$ and Gregório Varvakis ${ }^{1}$ (]) \\ ${ }^{1}$ Federal University of Santa Catarina, Brazil, and ${ }^{2}$ Maynooth University, Ireland}

\begin{abstract}
The need to innovate is relevant to many firms around the globe and is particularly pressing for those in emerging markets. They face global competition, are under-resourced, and suffer from weaker institutional support. It is suggested that to innovate successfully in this context, indigenous firms would benefit from focusing on managing their current knowledge base more efficiently. We know little about how knowledge management works outside developed economies and which knowledge governance mechanisms have more influence than others in the context of emerging economies. To address this gap, we explore how context may matter for the use of knowledge governance mechanisms and their effect on innovation performance in Brazilian firms. Using the survey data of 109 firms, structural equation modelling, and cluster analysis, our findings suggest that the joint application of knowledge-focused rewards, organizational design, and information and communication technologies that support knowledge processes is critical for boosting innovation performance. We discuss how the peculiarities of the Brazilian context may shape these findings. Our article contributes to the knowledge management and innovation literature by demonstrating that the joint effects of bundles of knowledge governance mechanisms and contextual variables should be explored in order to understand their impact on organizational outcomes.
\end{abstract}

KEYWORDS Brazil, context, innovation, knowledge governance mechanisms, knowledge management

\section{INTRODUGTION}

In recent decades Brazilian companies have been under pressure to become more innovative. On the one hand, opening up the market made them vulnerable to global competition with much better-resourced players (Rodríguez, Dahlman, \& Salmi, 2008). On the other hand, more educated and connected domestic customers have been demanding 'everything at the same time' - innovative products, 
increased quality, lower prices, and reasonable lead times (Frank, Cortimiglia, Ribeiro, \& de Oliveira, 2016; Thürer, Godinho Filho, Stevenson, \& Fredendall, 2013). Being better at innovation emerged as an essential answer to these challenges. At the same time, the Brazilian environment has been criticized for being non-conducive to innovation (Fleury, Fleury, \& Borini, 2013), with its weak institutional support and resource constraints. While there have been some positive changes recently in innovation-related government policies, the innovative capabilities of Brazilian firms remain quite low (Frank et al., 2016).

One of the explanations for this could be that Brazilian firms focused too much on leveraging their innovation performance through acquiring knowledge from abroad (Rodríguez et al., 2008), in particular through technology or equipment acquisition. However, this strategy is not an easy solution, as both the transfer and assimilation of foreign knowledge are challenging tasks (McDermott \& Pietrobelli, 2017). Indeed, it appears that Brazilian firms have been rather unsuccessful in exploiting external knowledge to boost their innovation performance (e.g., Frank et al., 2016). Therefore, several studies suggested that Brazilian firms could be better off by shifting their attention to finding value in and using more efficiently the knowledge they already have as the least expensive and most accessible way to boost their performance (e.g., McDermott \& Pietrobelli, 2017; Rodriquez et al., 2008). So, what can Brazilian firms do to manage their knowledge and become more efficient in innovating?

The knowledge-based view of the firm posits that innovation performance is a function of a firm's ability to acquire, integrate, and apply knowledge (Grant, 1996). Therefore, it responds to the question of how to improve innovation performance by focusing on various mechanisms that enhance a firm's knowledge base and stimulate knowledge-based processes. Different knowledge management practices, or knowledge governance mechanisms, were theorized in the literature (Foss \& Michailova, 2009), and some of them have been empirically demonstrated to be important to innovation performance (e.g., Alegre, Sengupta, \& Lapiedra, 2013; Darroch, 2005). However, this line of research does not sufficiently inform firms in emerging countries.

First, most of the studies on managing knowledge for innovation are based on data from developed countries (Inkinen, Kianto, \& Vanhala, 2015). At the same time, we do not have enough information about how these mechanisms work in different cultural and socio-economic contexts. This is potentially problematic, as several recent studies suggest that knowledge processes may work differently around the globe (e.g., Andreeva \& Ikhilchik, 2011; May \& Stewart, 2013; Michailova \& Hutchings, 2006), and thus may require different approaches to managing them.

Second, we still lack a comprehensive understanding of how different knowledge governance mechanisms function in comparison to each other and when applied together (Foss, Husted, \& Michailova, 2010). Do all knowledge management efforts provide an equally important contribution to innovation 
performance? Or, are some of them more important? Are individual knowledge governance mechanisms powerful on their own or do they need to be bundled with each other to produce some effect? When the resources are limited, what particular knowledge management approaches should be prioritized by managers in order to boost the innovation performance of their firms? This question about priorities is particularly important for organizations in emerging markets: they have additional pressure to innovate in order to be competitive with firms from developed markets, yet often they have only limited resources to do so.

In summary, the limited empirical evidence available does not allow us to develop clear recommendations for firms in emerging markets on what knowledge governance mechanisms would be most efficient to stimulate innovation in their specific context. Against this background, the purpose of our research is to explore the effects of knowledge governance mechanisms on innovation performance in Brazilian firms. In line with the call from Rodrigues, Duarte, and Carrieri (2012), we use the Brazilian context to add to general knowledge management theory on the contextual applicability of different management practices. We focus on four knowledge governance mechanisms: information and communication technologies, organizational design and organizational culture that are supportive of knowledge processes, and rewards for knowledge behaviors. We examine empirically the effects of these knowledge governance mechanisms on the innovation performance of 109 Brazilian firms. Based on SEM-PLS analysis and cluster analysis, we demonstrate that in our sample, the joint application of knowledge-focused rewards, organizational design, and information and communication technologies (ICT) that support knowledge processes leads to superior innovation performance.

Our article contributes to the knowledge management and innovation literature in several ways. First, it explores how peculiarities of the country context may influence the use and efficiency of knowledge management practices. Second, it demonstrates that the joint effects of bundles of knowledge governance mechanisms should be analyzed in order to understand their impact on innovation performance. Finally, it contributes to the literature on managing in emerging markets, and in Brazilian firms in particular, by demonstrating what knowledge governance mechanisms and their combinations are particularly powerful in this context.

\section{THEORETIGAL BACKGROUND AND HYPOTHESES}

\section{Putting Knowledge Governance in Context}

The literature has widely acknowledged the importance of context in management studies and called for more context-informed research (e.g., Meyer, 2015; Michailova, 2011; Whetten, 2009). In the knowledge management field, several studies have argued that context may influence both the applicability and the 
efficiency of knowledge governance mechanisms (e.g., Andreeva \& Ikhilchik, 2011; Bruton, Dess, \& Janney, 2007; Glisby \& Holden, 2003; May \& Stewart, 2013; Michailova \& Sidorova, 2010). For example, the institutional environment has been theorized to influence knowledge management in organizations by defining expectations and requirements about what knowledge-related actions can be considered legitimate and appropriate and by providing incentives and resources for knowledge processes (Lu, Tsang, \& Peng, 2008). It has been proposed that the availability of resources in the external environment influences the capabilities firms tend to develop in order to be competitive (Wan, 2005).

At the same time, knowledge management research has been criticized recently for the tendency to overlook the context in which the data was collected and its potential impact on research findings (Sergeeva \& Andreeva, 2016). For example, while there are a number of studies of knowledge management in Brazilian organizations (Dominguez Gonzalez \& Martins, 2014; Lakshman \& Parente, 2008; Oliva, 2014) they barely discuss the peculiarities of managing knowledge in this context. To address these concerns, we explored what aspects of Brazilian context might shape the patterns of use and the efficiency of knowledge governance mechanisms in Brazilian organizations.

\section{Knowledge Governance Mechanisms in the Brazilian Context: What is Used?}

The knowledge governance approach posits that to exploit the competitive potential of knowledge as a strategic resource, managers have to direct intra-organizational knowledge processes through the deployment of various governance mechanisms (Foss \& Michailova, 2009). We suggest that the various knowledge governance mechanisms discussed in the literature can be broadly divided into 'people-focused' and 'process- or infrastructure-focused' mechanisms. The first group of mechanisms is based on the idea that people are the key possessors of knowledge in organizations and the key agents of knowledge processes (e.g., Andreeva \& Sergeeva, 2016). Therefore, knowledge processes will run efficiently if employees are willing to engage in them. Rewards and organizational culture are widely discussed as key mechanisms to address this motivational challenge. The approach that stands behind the second group of practices suggests that organizations need to have an appropriate infrastructure and the organizational processes need to be tuned in a way to enable and support knowledge processes (e.g., Foss, Pedersen, Reinholt, \& Stea, 2015). Among 'infrastructure-focused' mechanisms, two have received the most attention: information and communication technologies and organizational design methods that enable knowledge processes. We shall now explore what each of the mechanisms means and how peculiarities of Brazilian context may influence their use in Brazilian organizations.

Information and communication technologies include various hardware and software applications and systems that allow users to access, store, and share codified 
knowledge. Therefore, by their very nature they can be potent enablers of knowledge processes in organizations, assisting members of the organization to access each other's knowledge, reducing time and distance gaps between employees and enabling them to combine their knowledge in a fast and accessible manner (Davenport, De Long, \& Beers, 1998; Zack, 1999).

The Brazilian context appears to be quite favorable for the wide application of ICT in local organizations. The Brazilian government has recently invested substantially in the development of ICT along two main pathways. First, it has been offering financial support to firms willing to engage in technology acquisition projects (Sparkman, 2015). Second, it has been actively promoting development of skills related to the use of technology (see, for example, the 'National Education Basis and Principles Law', a guideline for education in Brazil). These efforts made technologies more accessible for businesses, as well as making both Brazilian firms and employees more technologically savvy and able to manage technology in a more efficient way. This is evidenced by the significant growth in the adoption of ICT and its positive impact on Brazilian firms' productivity (e.g., Commander, Harrison, \& Menezes-Filho, 2011), as well as by the increase in the Brazilian Technology Achieving Index in recent years (Sparkman, 2015). In addition to this, local ICT companies have been focusing on developing various software packages that support knowledge management (Barradas \& Campos, 2010). Based on this we can hypothesize that, by having access to more resources and enhanced skills, a large number of Brazilian firms are engaged in initiatives for the deployment of ICT-based mechanisms that also help with knowledge processes:

Hypothesis 1: ICT that support knowledge processes will be widely used among Brazilian firms.

Organizational design decisions that serve both to divide the work and to coordinate efforts across an organization may provide opportunities for employees to share knowledge, exchange ideas, and learn from each other, or, on the contrary, inhibit these processes (Grant, 1996; Miles, Snow, Mathews, Miles, \& Coleman, Jr., 1997). For example, the use of cross-functional teams may stimulate knowledge sharing across departments and increase innovativeness by bringing together people with different skills and backgrounds who have multiple perspectives on a problem and complementary information, whereas too hierarchical a structure slows knowledge flows (Davenport et al., 1998; Manhães \& Davila, 2016; Miles et al., 1997).

Organizational design approaches that are common in Brazil might be problematic in this respect. Brazilian organizations tend to have excessively hierarchical organizational structures with a punitive system of control (Amado \& Vinagre, 1991). This trend is naturally enhanced by Brazilian national culture, which is characterized by high power distance and moderately high uncertainty avoidance (House, Hanges, Javidan, Dorfman, \& Gupta, 2004). In addition, the low 
institutional collectivism of that culture (House et al., 2004; Osland, De Franco, \& Osland, 1999) makes interdepartmental communication and collaboration potentially problematic, particularly in bigger organizations. In light of this, we can hypothesize that:

Hypothesis 2: Knowledge-focused organizational design will not widely used by Brazilian firms.

Among 'people-focused' knowledge governance mechanisms, one of the cornerstones is creating stimuli for employees to engage in knowledge behaviors. One of the ways to stimulate employees to share and create knowledge - and, ultimately, to innovate - is to offer rewards for these behaviors, as they tell them what is expected and encouraged (Barros \& Lazzarini, 2012; Foss et al., 2015). Such rewards may include bonuses, additional points for promotion, or public recognition for employees' contributions to knowledge processes, e.g., active knowledge sharing with colleagues, developing new ideas, or useful applications of recently created knowledge.

These ideas seem to conflict with beliefs that are common among Brazilian managers, who tend to avoid additional monetary incentives, fearing that employees might develop 'habituality' - internalize the idea that incentives are automatically incorporated into their salary (Fleury \& Fleury, 1997). Rewards for knowledge-related behaviors naturally fall into the category of additional incentives that are not included in the basic remuneration package. In addition, pay for performance, of which rewards for knowledge-related behaviors are an example, has been reported as being practiced in Brazilian organizations to a very limited extent due to difficulties in its implementation (Fischer \& de Albuquerque, 2005). Such difficulties can be explained by some features of Brazilian culture: collectivism makes both identifying and rewarding individual contribution less socially acceptable, and high power distance may undervalue individual performance at the lower levels of the hierarchy (Fischer et al., 2007). Based on these considerations, we hypothesize that:

\section{Hypothesis 3: Knowledge-focused rewards will not be widely used in Brazilian firms.}

Knowledge behaviors can also be incentivized in a different way: through developing and maintaining an organizational culture that imposes specific values and norms, promotes certain role models, and encourages the behaviors that follow these role models (Alavi, Kayworth, \& Leidner, 2006; De Long \& Fahey, 2000). Several cultural values and norms were proposed in the literature as being particularly relevant to promote knowledge sharing and creation, such as openness to new ideas, flexibility, trust, collaboration between units, learning, and open sharing of both successful and unsuccessful lessons learned (e.g., Alavi et al., 2006; Ellonen, Blomqvist, \& Puumalainen, 2008). 
Brazilian national culture appears to be naturally supportive of many of these norms. First, it is characterized by high in-group collectivism - the degree to which individuals express pride, loyalty, and cohesiveness in their families or close groups (House et al., 2004). Brazilians tend to see their relationships with other businesspeople as interpersonal in nature and place a high value on these relationships (Turner \& Kleiner, 1996), as well as valuing the interests of the group higher than individual interests (Lenartowicz \& Johnson, 2003). These cultural features promote trust, loyalty, and commitment among employees that naturally facilitate informal interactions among employees that are vital for knowledge sharing and knowledge creation. Another aspect of Brazilian culture that supports informal knowledge exchanges and individual creativity is jeitinho brasileiro - an ability to explore alternative ways to manage difficulties, flexibility to improvise in the face of obstacles, or a rule for the changing of rules (Amado \& Vinagre, 1991; Lee Park, Fracarolli Nunes, Muratbekova-Touron, \& Moatti, 2018). In addition to this, House et al. (2004) found that Brazilian leaders were on average more team-oriented and participative than leaders from other countries. Building on the idea that the culture of an organization starts with its leaders, one may suggest that open and informal (in other words, knowledge-management-friendly) organizational cultures would be quite common in Brazil. Taking all of this into account, we hypothesize that:

Hypothesis 4: Knowledge-friendly organizational cultures will be widely used in Brazilian firms.

\section{Knowledge Governance Mechanisms in the Brazilian Context: What is More Efficient?}

The next question is: Which of these knowledge governance mechanisms would be the most effective in enhancing organizational innovation in Brazilian organizations? The extant research explored a variety of knowledge governance mechanisms and demonstrated that each of them might have a positive impact on employees' knowledge-related behaviors (e.g., Andreeva \& Sergeeva, 2016; Foss et al., 2015) and, consequently, on organizational innovation (e.g., Alegre et al., 2013; Darroch, 2005). Therefore, an organization may be tempted to use many knowledge governance mechanisms - or as many as possible - to ensure the most efficient use of its knowledge resources and to boost its innovation performance. At the same time, in reality, most organizations have limited resources to invest in managing knowledge, so the question of which interventions to prioritize becomes important. Which of the knowledge governance mechanisms matter most? Are there any particularly powerful combinations of these mechanisms that organizations should focus on? This question is particularly relevant for firms in emerging markets like Brazil, as they have limited resources with which to compete. 
Existing literature on Brazil, though providing rich descriptions of the context in which knowledge governance mechanisms are to function, does not allow for clear-cut propositions on which of them would work best in this context. For example, one may hypothesize that ICT mechanisms would be particularly efficient in Brazil as they are complemented by a technologically savvy workforce (Sparkman, 2015). At the same time, there is some evidence that for cultural reasons Brazilians prefer face-to-face communication channels over technologyenabled ones for knowledge sharing (Ardichvili, Maurer, Li, Wentling, \& Stuedemann, 2006) and thus ICT for knowledge management may have no impact, or even a negative impact, on performance (Lakshman \& Parente, 2008). Alternatively, one may hypothesize that knowledge-focused organizational design mechanisms, such as cross-functional teams, would be particularly powerful for enhancing innovation in Brazilian organizations as by their nature they solve the problems of traditional hierarchical structures. However, their effect might be undermined by high in-group collectivism on the part of employees and over-controlling on the part of managers (Amado \& Vinagre, 1991; Osland et al., 1999). A knowledge-friendly organizational culture, on the one hand, may be a particularly efficient tool to enhance knowledge processes in Brazilian organizations by offsetting the drawbacks of their overly hierarchical organizational structures. On the other hand, if such organizational culture is indeed so common across Brazilian organizations due to a shared national culture, would it make a significant difference for innovation performance compared to local competitors? These examples vividly illustrate the idea that contextual pressures are often inconsistent and even conflicting, and that the Brazilian context is particularly full of paradoxes (Caldas, 2006; Story \& Reis, 2014).

Instead of looking at the efficiency of single, isolated mechanisms, an alternative approach is to consider how they work in combination. The idea that various organizational activities can be considered as systems of interdependent elements or configurations that affect performance beyond the influence of their individual elements has been explored in various fields of management research (e.g., Gruber, Heinemann, Brettel, \& Hungeling, 2010; Meyer, Tsui, \& Hinings, 1993; Youndt, Subramaniam, Snell, 2004). Within the knowledge management domain, several arguments support the idea that knowledge governance mechanisms should be analyzed in their interactions with each other. First, theories behind 'peoplefocused' and 'infrastructure-focused' approaches to managing knowledge appear to be complementary, as ideally an organization needs to have both - employees motivated to engage in knowledge sharing and creation, and proper processes that allow employees to do so (e.g., Andreeva \& Kianto, 2012; Foss et al., 2015). For example, to share knowledge, motivated employees also need to have space and opportunities to meet their colleagues (Andreeva \& Sergeeva, 2016). Second, according to signaling theory (Connelly, Certo, Ireland, \& Reutzel, 2011), multiple knowledge governance mechanisms have the potential to produce jointly a clearer and more consistent message to employees about what is important for the 
organization. These arguments could work for Brazilian organizations as well. Based on these considerations, we hypothesize that:

Hypothesis 5: Brazilian organizations using a combination of knowledge governance mechanisms will exhibit better innovation performance than those that focus on single knowledge governance mechanisms.

\section{METHODS}

\section{Sample}

Data was collected in the state of Santa Catarina, one of the more prosperous Brazilian states, located in the southern part of the country. Santa Catarina hosts approximately 50,000 firms (FIESC, 2017). A key partner for this research was the Industry Federation of Santa Catarina State (FIESC), participation in which is mandatory for all businesses. This research was included in the FIESC annual research agenda and they managed the data collection process. Data collection is challenging in Brazil, as in many developing and emerging countries, as companies do not usually want to participate in research surveys, often due to the lack of trust in external research parties and lack of understanding of how the data will be used. To overcome this barrier, we decided to target the firms that had collaborated with FIESC in the past in different ways, for example, by participating in FIESC business-related surveys. This ensured that the target companies had sufficient trust in FIESC to share their internal information. After identifying this group of companies in the database, we selected only the firms that had the direct email contacts for their $\mathrm{CEO}$ or a top-level manager registered in the FIESC database. This non-probabilistic sample aimed to improve the efficiency of data collection and to reduce the risks of the common bias method (Podsakoff, MacKenzie, \& Podsakoff, 2012). The final sample population consisted of 1548 cross-industry firms. Data collection was carried out between November 2015 and April 2016, using an online survey sent by email by the FIESC. The first email was sent in November 2015 and it contained a brief description of the purpose of the research, ethical guidelines, and our commitment to returning a summary report with aggregate results after data analysis. We asked our correspondents (CEOs and top-level managers) either to answer the survey themselves or to delegate it to a person with knowledge of their organization's systems. We provided a telephone number for assistance and support. Three reminders were sent: in December 2015, in the middle of January 2016, and at the beginning of March 2016. We collected 146 responses, representing a response rate of 9.3\%. We excluded 35 responses as they had provided incomplete data, and two more provided unengaged answers, achieving a usable sample of 109 responses for further analysis.

Most of our respondents represented top management (46\%), and another significant group held middle-management positions (41\%). The most represented 
industries in our sample were foods and beverages (35\%), metallurgy (9\%), textiles $(8 \%)$, and ICT $(7 \%)$, which reflects the key industry sectors in the state of Santa Catarina. In terms of size, the biggest group of companies in our sample belongs to what is defined in Brazil as 'small business' - from 20 to 99 employees (SEBRAE, 2017). On average, companies in our sample are bigger than in the original business population in Santa Catarina, which is dominated by micro-firms.

\section{Measures}

Knowledge governance mechanisms. We examined several potentially relevant scales available in the literature and discussed them with three academic experts and three practitioners from Brazil. Taking account of this analysis, we chose the scales developed by Kianto and Andreeva (2014), for two reasons: they fit best with the research goals of our project, and their wording and structure are well understood in the Brazilian context. These scales measure the four governance mechanisms discussed in this paper.

Innovation performance. To measure innovation performance, we decided to use subjective perceptual indicators, following the approach that has been used in other studies in Brazil (Figueiredo, 2011) and in other contexts (e.g., BuenecheaElberdin, Kianto, \& Sáenz, 2018). Several reasons guided our choice. First, we needed measures that would be applicable to businesses in our context: an emerging economy and a business population dominated by small firms. Second, we were looking for measures that would allow meaningful comparison of companies from different industry sectors and of different sizes. Some authors have suggested that indicators related to patents and R\&D expenditure are less relevant for companies from developing and emerging countries, as these firms often do not have designated R\&D structures and perform most of their innovation activities through engineering, operation, or marketing units (Figueiredo, 2005). We believe these arguments are also valid for the smaller firms that dominated our target population. Objective indicators also tend to neglect activities of imitation, copying, adaptation, process, or organizational model adoption, which are all important parts of the innovation process in firms in emerging markets (Figueiredo, 2005). Moreover, firms in emerging economies often patent less, both because they tend to focus on incremental innovation (Frank et al., 2016) and because the intellectual property rights systems are less developed (Barros, 2015). Therefore, patenting patterns may not correlate with firm innovativeness in emerging markets. Based on these considerations, we rejected objective indicators of innovation and opted for subjective ones that have been demonstrated to correlate strongly with objective measures (Jennings \& Young, 1990) and offer the benefit of allowing comparisons across firms and contexts (Song, Droge, Hanvanich, \& Calantone, 2005). We used the perceived innovation performance 
scale of Weerawardena (2003) that has been widely validated in previous studies (e.g., Buenechea-Elberdin et al., 2018).

As the original scales were in English, they were translated into Portuguese following the several-stage procedure recommended for cross-national research, with back-translation by an independent expert (Harkness et al., 2003). Responses to knowledge governance and innovation questionnaire items were scored on a five-point Likert-type scale measuring respondents' agreement or disagreement with proposed statements ( $1=$ strongly disagree, $5=$ strongly agree).

Controls. We also included two control variables that may have an impact on innovation performance - firm size (number of employees) and firm age (Chandy \& Tellis, 2000). We used a logarithm transformation of these variables to ensure the normality of the distribution.

\section{Assessment of Potential Biases}

We followed a set of both procedural and statistical remedies to control and ensure that common method bias $(\mathrm{CMB})$ would not influence our results, following suggestions from Podsakoff et al. (2012). First, the online survey was managed by FIESC and performed as a part of the annual survey plan. This served to reduce the effects of item context by providing respondents with the same data collection standards as they are used to dealing with (e.g., communication style and channel). Second, practitioners from FIESC, who are usually involved in surveys for industry diagnosis, helped to improve our translations of the scale items to ensure that the wording of our questions was clear. Third, the survey process was designed to guarantee respondent anonymity, and we explicitly gave assurances of that before and during the survey to increase the likelihood of honest answers. Fourth, we involved highly experienced respondents, familiar with innovation and business management issues, to evaluate study variables. These procedural measures decrease the risks of CMB.

After data collection, we performed statistical analysis to evaluate the existence of CMB. Following Podsakoff et al. (2012), we tested a model that included an additional unmeasured latent factor to represent CMB. As suggested by Liang, Saraf, $\mathrm{Hu}$, and Xue (2007), in this model items were permitted to load both on the unmeasured latent factor and their theoretical constructs. The loadings on the unmeasured latent factor were lower than the loadings on the construct factors. In addition, following Kock (2015), we tested measurement models and checked that variance inflation factors (VIF) for each construct factor were lower than 3.3. These statistical procedures taken together suggested that CMB is unlikely to be a serious concern in this research.

To test for nonresponse bias, we compared the answers of early and late respondents (those who responded during the first month, 23\% of the sample, vs. the last month of the survey, $10 \%$ of the sample) using discriminant analysis 
(Armstrong \& Overton, 1977). No significant differences were found in any of the indicators, suggesting that nonresponse bias should not be a concern.

\section{Method of Analysis}

We addressed our research questions with partial least squares structural equation modelling (SEM-PLS) and cluster analysis, using SmartPLS and SPSS software respectively. We chose SEM-PLS as the most relevant technique as it allows testing causal paths between latent variables and identifying the collective strength of multiple variables (Creswell, 2013) and is best suited to relatively small datasets with non-normally distributed data (Lowry \& Gaskin, 2014). In this analysis, we followed the best practices suggested by Ringle, Sarstedt, and Straub (2012).

To identify potential bundles of knowledge governance mechanisms, we used cluster analysis, a technique that makes it possible to identify groups with similar characteristics and has been previously employed for studying configurations in organizations (e.g., Gruber et al., 2010; Youndt et al., 2004). We followed the procedures and best practices outlined by Ketchen and Shook (1996) and Hair, Black, Babin, Anderson, and Tatham (2006). To explore the differences between the identified clusters, we used either the usual one-way ANOVA or, if homogeneity of variances was violated, Welch ANOVA and two different post hoc criteria (Tamhane's T2 and Games-Howell tests, both at $\mathrm{p}<0.05$ ), as our group sizes were unequal (Moder, 2010). Finally, we used stepwise regression to cross-validate our interpretation of findings from cluster analysis.

\section{RESULTS}

\section{Measurement Model}

First, a measurement model analysis was conducted to ensure construct reliability, convergent validity, and discriminant validity. Various characteristics of our scales (see Table 1) were all above the recommended thresholds (e.g., Fornell and Larcker, 1981; Hair et al., 2006). Furthermore, as shown in Table 1, the square root of AVE values are higher than shared variance between variables provided evidence of good discriminant validity (Henseler, Hubona, \& Ray, 2016). We also verified the absence of multicollinearity by calculating the VIF for each indicator (Hair et al., 2006). Our analysis demonstrates the reliability and validity of the measurement model for representing the concepts discussed in this study.

\section{Descriptive Analysis: Exploring the Use of Individual Knowledge Governance Mechanisms}

To explore Hypotheses 1-4, it is important to bear in mind the meaning of the scale against which we measured our survey items. We asked our respondents to 
Table 1. Scales' characteristics, descriptive statistics and correlations between variables of the study

\begin{tabular}{|c|c|c|c|c|c|c|c|c|c|c|c|c|c|c|}
\hline & & \multirow[b]{2}{*}{$\begin{array}{l}\text { Cronbach's } \\
\text { Alpha }\end{array}$} & \multirow[b]{2}{*}{$\begin{array}{l}\text { Composite } \\
\text { Reliability }\end{array}$} & \multirow[b]{2}{*}{ rho $A$} & \multirow[b]{2}{*}{$A V E$} & \multirow[b]{2}{*}{ Mean } & \multirow[b]{2}{*}{ Std. Dev. } & \multicolumn{7}{|c|}{$\begin{array}{c}\text { Correlations* and p-values (in brackets), } \\
\text { Square root of AVE in diagonal }\end{array}$} \\
\hline & & & & & & & & 1 & 2 & 3 & 4 & 5 & 6 & 7 \\
\hline 1 & Firm Age & & & & & 30.49 & 23.83 & 1 & & & & & & \\
\hline 2 & Firm Size & & & & & 1,371 & 5,581 & $\begin{array}{c}0.443 \\
(0.000)\end{array}$ & 1 & & & & & \\
\hline 3 & ICT that supports knowledge processes & 0.83 & 0.88 & 0.88 & 0.60 & 3.45 & 0.88 & $\begin{array}{c}0.044 \\
(0.646)\end{array}$ & $\begin{array}{c}0.135 \\
(0.161)\end{array}$ & 0.77 & & & & \\
\hline 4 & Knowledge-focused organisational design & 0.80 & 0.86 & 0.81 & 0.56 & 3.83 & 0.78 & $\begin{array}{r}-0.111 \\
(0.250)\end{array}$ & $\begin{array}{c}-0.012 \\
(0.901)\end{array}$ & $\begin{array}{c}0.408 \\
(0.000)\end{array}$ & 0.78 & & & \\
\hline 5 & Knowledge-focused rewards & 0.80 & 0.86 & 0.87 & 0.60 & 2.78 & 0.95 & $\begin{array}{r}-0.071 \\
(0.461)\end{array}$ & $\begin{array}{c}-0.091 \\
(0.347)\end{array}$ & $\begin{array}{c}0.480 \\
(0.000)\end{array}$ & $\begin{array}{c}0.468 \\
(0.000)\end{array}$ & 0.75 & & \\
\hline 6 & $\begin{array}{l}\text { Knowledge-friendly organisational } \\
\text { culture }\end{array}$ & 0.88 & 0.91 & 0.90 & 0.63 & 3.93 & 0.76 & $\begin{array}{r}-0.364 \\
(0.000)\end{array}$ & $\begin{array}{r}-0.280 \\
(0.003)\end{array}$ & $\begin{array}{c}0.329 \\
(0.000)\end{array}$ & $\begin{array}{c}0.626 \\
(0.000)\end{array}$ & $\begin{array}{c}0.454 \\
(0.000)\end{array}$ & 0.79 & \\
\hline 7 & Innovation Performance & 0.87 & 0.91 & 0.89 & 0.66 & 3.58 & 0.79 & $\begin{array}{r}-0.193 \\
(0.044)\end{array}$ & $\begin{array}{c}0.006 \\
(0.949)\end{array}$ & $\begin{array}{c}0.354 \\
(0.000)\end{array}$ & $\begin{array}{c}0.442 \\
(0.000)\end{array}$ & $\begin{array}{c}0.243 \\
(0.011)\end{array}$ & $\begin{array}{c}0.375 \\
(0.000)\end{array}$ & 0.81 \\
\hline
\end{tabular}

Note: * To calculate correlations we used the Ln of Firm Age and Firm Size. 
Table 2. Usage of knowledge governance mechanisms

\begin{tabular}{lccc} 
& \multicolumn{3}{c}{$\%$ of the sample } \\
\cline { 2 - 4 } Knowledge governance mechanism & $\begin{array}{c}\text { low usage } \\
(\leq 2.5)\end{array}$ & $\begin{array}{c}\text { inconsistent/irregular usage } \\
(2.5<x \leq 3.5)\end{array}$ & $\begin{array}{c}\text { active usage } \\
>3.5\end{array}$ \\
\hline ICT that supports knowledge processes & 18.4 & 32.1 & 49.5 \\
Knowledge-focused organizational design & 9.2 & 20.2 & 70.6 \\
Knowledge-focused rewards & 45.9 & 36.7 & 17.4 \\
Knowledge-friendly organizational culture & 6.4 & 19.3 & 74.3 \\
\hline \hline
\end{tabular}

indicate to what extent the statements describing different knowledge governance mechanisms relate to their organization, on a scale from 1 ('strongly disagree') to 5 ('strongly agree'). The middle point of the scale (3) therefore indicates 'neither agree nor disagree' and may be interpreted as conveying the fragmented, inconsistent, or irregular use of a knowledge governance mechanism (cf. Andreeva, Vanhala, Sergeeva, Ritala, \& Kianto, 2017). Based on this consideration, the groups of low, inconsistent/irregular, and active use of the relevant mechanism could be identified (with arbitrary cut-off points of 2.5 and 3.5, respectively). The distribution of the firms in our sample between these groups is represented in Table 2.

Table 2 suggests that organizational culture and organizational design are widely used knowledge governance mechanisms among Brazilian firms, with over $70 \%$ of the respondents reporting their active use. Therefore, Hypothesis 4 is supported, while Hypothesis 2 is not. Knowledge-focused rewards are clearly underutilized in our sample, with $46 \%$ of firms reporting their low usage, and only $17 \%$ using them actively (hence, Hypothesis 3 is supported). Finally, ICTbased mechanisms fall into the middle category, with almost $50 \%$ of the firms reporting their active use, and the other $32 \%$ using them to some extent. Therefore, $\mathrm{H} 1$ is partially supported.

\section{Structural Model: Efficiency of Individual Knowledge Governance Mechanisms}

A bootstrapping procedure was performed (with 5000 bootstrap samples) in order to obtain and present confidence intervals about each construct and path in the model. As shown in Table 3, our model yielded a good SRMR index of 0.088 (Henseler et al., 2016). The value of adjusted $\mathrm{R}^{2}$ indicates that our model explains $24.6 \%$ of variance in innovation performance. This explanatory power is in line with previous studies of knowledge management as antecedent for innovation performance, where explained variance varies from 15 to $40 \%$ (e.g., Barros \& Lazzarini, 2012; Darroch, 2005; Ellonen et al., 2008; Inkinen et al., 2015) and it is satisfactory considering that knowledge management is just one of the potential 
Table 3. Path coefficients, $\rho$-values, and effect sizes (full sample)

\begin{tabular}{lccc} 
Dependent variable: Innovation Performance & Path Coefficient & Signif. $(\rho)$ & Effect size $\left(f^{2}\right)$ \\
\hline Firm Age & -0.169 & 0.079 & 0.030 \\
Firm Size & 0.075 & 0.418 & 0.006 \\
ICT that supports knowledge processes & 0.234 & 0.032 & 0.053 \\
Knowledge-focused organizational design & 0.299 & 0.018 & 0.064 \\
Knowledge-focused rewards & -0.046 & 0.634 & 0.002 \\
Knowledge-friendly organizational culture & 0.102 & 0.467 & 0.006 \\
\hline Adjusted $\mathrm{R}^{2}$ & 0.246 & & \\
$\mathrm{Q}^{2}$ & 0.155 & & \\
\hline \hline
\end{tabular}

antecedents for innovation (Crossan \& Apaydin, 2010). The value of StoneGeisser-criterion $Q^{2}=0.155$ indicates acceptable predictive relevance (Stone, 1974) of our model.

Analysis of the model suggested the existence of statistically significant paths with relatively small effects from organizational design mechanisms $(\beta=0.299, \rho=$ $\left.0.018, f^{2}=0.064\right)$ and ICT mechanisms $\left(\beta=0.234, \rho=0.032, f^{2}=0.053\right)$ to innovation performance. People-focused mechanisms (knowledge-based rewards and organizational culture) appeared to be not significant for innovation performance.

However, this overall model provides insights only into the average effects of individual knowledge governance mechanisms across all firms in our sample, aggregating potentially different bundles of mechanisms and their potentially different innovation effects. Therefore, we now turn to explore such bundles.

\section{Cluster Analysis: Identifying Bundles of Knowledge Governance Mechanisms}

To identify bundles of knowledge governance mechanisms, we followed the twostep clustering procedure recommended by Ketchen and Shook (1996), and Hair et al. (2006). First, we applied hierarchical clustering to determine the appropriate number of clusters. As suggested by Ketchen and Shook (1996), we identified cluster solutions using both Ward and complete linkage methods and compared them. Using the elbow criterion, both methods suggested that the three-cluster solution was optimal. Next, we used group centroids from the hierarchical procedure as initial cluster seeds to perform the k-means clustering procedure. The obtained three cluster solution was then validated with $75 \%$ of the sample, randomly selected from the total sample.

Following Ketchen and Shook (1996), we ran the full analysis twice - with standardized and unstandardized variables; the latter option was appropriate as our variables were measured on the same scale. Clustering solutions were consistent between each of the different approaches, indicating a robust and generalizable 


\begin{tabular}{lccr} 
& \multicolumn{2}{c}{ Cluster means* } \\
\cline { 2 - 4 } & $\mathbf{1}$ & $\mathbf{2}$ & $\mathbf{3}$ \\
\hline Clustering variables: Knowledge governance mechanisms & & & 3.35 \\
ICT that supports knowledge processes & 2.77 & 4.28 & 4.11 \\
Knowledge-focused organisational design & 2.87 & 4.26 & 2.66 \\
Knowledge-focused rewards & 1.84 & 3.89 & 4.11 \\
Knowledge-friendly organisational culture & 3.12 & 4.41 & 3.55 \\
Outcome variable: & & 3.96 & 52 \\
Innovation Performance & 3.23 & 29 & \\
Cluster size $(\mathcal{N})$ & 28 & & \\
\hline \hline
\end{tabular}

Note: * All variables are unstandardized, on a Likert scale from 1 to 5.

cluster solution. We present below the analysis based on unstandardized variables as it enables clearer interpretations of the resulting cluster solutions based on our scales and based on the Ward method. Table 4 presents the cluster means for each of the four knowledge governance mechanisms that were used for clustering, as well as for innovation performance as outcome variable.

We found statistically significant differences between the clusters in the use of each of the knowledge governance mechanisms as evidenced by $F(2,106)=$ 40.689, $\rho=0.000$ for knowledge-friendly organizational culture; $F(2,106)=$ 86.709, $\rho=0.000$ for knowledge-focused rewards; $F(2,106)=62.138, \rho=0.000$ for knowledge-focused organizational design, and Welch's $F(2,60.430)=44.887$, $\rho=0.000$ for ICT that supports knowledge processes. Both Tamhane's T2 and Games-Howell post hoc tests revealed that the use of all knowledge governance mechanisms was statistically significantly higher in Cluster 3 than in Cluster 1 (at $\rho$ varying between 0.000 and $0.008^{[1]}$ ) and in Cluster 2 than in Clusters 1 and 3 (at $\rho$ varying between 0.000 and 0.029 ), except for organizational design, for which Clusters 2 and 3 were not significantly different $(\rho=0.447)$. In other words, in comparative sense, Cluster 1 exhibits the lowest use of all knowledge governance mechanisms, Cluster 3 shows moderate-level use of three mechanisms and high-level use of organizational design, while Cluster 2 reveals high levels of all four knowledge governance mechanisms.

\section{Identified Clusters and Innovation Performance}

To externally validate this cluster solution, as well as to explore whether different bundles of knowledge governance mechanisms have a differentiated effect on innovation performance, we compared the innovation performance means of identified clusters. $F(2,106)=6.794, \rho=0.002$ indicated that there was a statistically significant difference between the clusters. Post hoc tests presented in Table 5 revealed that innovation performance was statistically significantly higher in 
Table 5. Comparison of innovation performance means between clusters

\begin{tabular}{|c|c|c|c|c|}
\hline \multirow{3}{*}{$\begin{array}{l}\text { Cluster } \\
\text { No. (i) }\end{array}$} & \multirow[b]{3}{*}{ Innovation Performance (Means) } & \multicolumn{3}{|c|}{$\begin{array}{c}\text { Mean differences (i-j), } \\
\text { Significance levels } \rho, \\
\text { (Effect sizes - Hedges' } \mathrm{g} \text { - are indicated in brackets) }\end{array}$} \\
\hline & & \multicolumn{3}{|c|}{ Cluster No. (j) } \\
\hline & & 1 & 2 & 3 \\
\hline 1 & 3.23 & - & & \\
\hline 2 & 3.96 & $0.73, \rho=0.003(0.934)$ & - & \\
\hline 3 & 3.55 & $0.32, \rho=0.289$ & $-0.41, \rho=0.036(0.598)$ & - \\
\hline
\end{tabular}

Cluster 2 (3.96 \pm 0.66$)$ than in both Cluster 1 (3.23 $\pm 0.89, \rho=0.003)$ and Cluster 3 (3.55 $\pm 0.7, \rho=0.036)$, with between group effect sizes (Hedges' $g$ ) of 0.934 and 0.598 respectively (Hedges \& Olkin, 1985; Lenhard \& Lenhard, 2016). These effect sizes indicate the large effect between Clusters 2 and 1, and an intermediate effect between Clusters 2 and 3 (Cohen, 1988). There was no statistically significant difference in innovation performance between Clusters 1 and $3(\rho=0.289)$.

\section{Interpretation of Identified Clusters}

The scores of the clusters need to be interpreted having in mind the meaning of our measurement scale, in which, as we suggested above, the scores around the middle point of the scale (between 2.5 and 3.5) may indicate fragmented, inconsistent, or irregular use of a knowledge governance mechanism (cf. Andreeva et al., 2017). To facilitate clusters' comparison and interpretation, Figure 1 visualizes the differences between clusters.

Based on their approach to use certain bundles of knowledge governance mechanisms, we labeled the identified clusters as ' $K M$ neglects', ' $K M$ stars', and ' $K M$ moderates'. While these labels may oversimplify the actual cluster solutions, we suggest that they make the identified bundles more easily accessible and facilitate discussion of our findings.

Cluster 1: 'KM neglects'. Firms in this cluster have the lowest scores for all knowledge governance mechanisms among our clusters. They certainly do not use knowledgefocused rewards, and for other three mechanisms they float in the 'irregular/fragmented' usage zone. The use of this approach to managing knowledge clearly leads to lower levels of innovation performance.

Cluster 2: 'KM stars'. Firms in this cluster employ a full range of knowledge governance mechanisms. The rather intensive use of knowledge-focused rewards is a distinctive feature of this cluster: firms in other clusters mostly appear to disregard this particular mechanism. Our empirical data indicates that organizations that apply this full bundle of knowledge governance mechanisms lead in innovation 


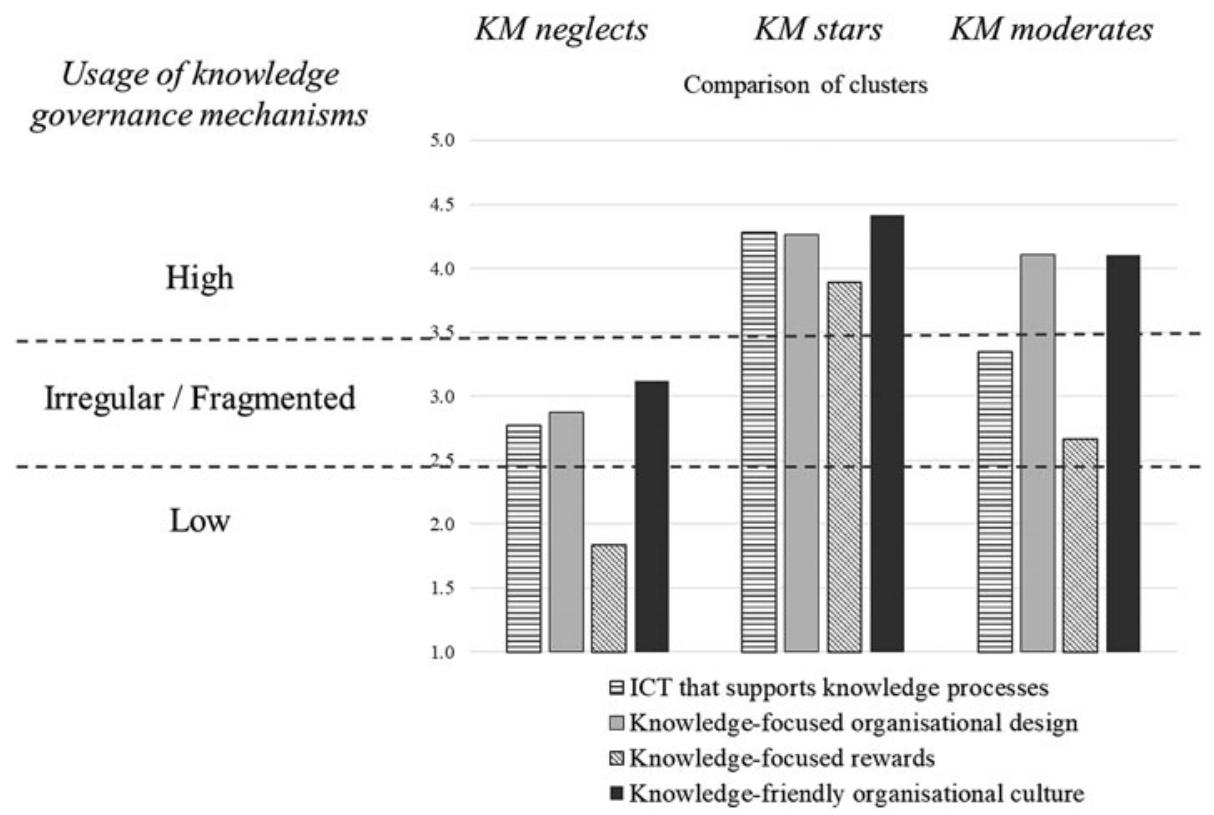

Figure 1. Comparison of clusters

performance, outperforming both those that do not do much about managing their knowledge and those that use a number of knowledge mechanisms to a moderate extent but disregard knowledge-focused rewards.

Cluster 3: 'KM moderates'. Firms in this group actively use two out of four of the knowledge governance mechanisms we studied, being particularly strong in the implementation of knowledge-friendly organizational design (at the same level as 'KM stars') and developing knowledge-friendly culture. Their use of ICT and knowledge-focused rewards is fragmented/irregular, with a bit more active use of ICT and more neglect of rewards. This approach underperforms 'KM stars' in terms of innovation. Interestingly, though this approach to knowledge governance appears to be much more developed than 'KM neglects', in terms of innovation outcomes it was not found to be statistically different from it.

These findings suggest that Hypothesis 5 is not fully supported. On the one hand, 'KM stars' that use full range of knowledge governance mechanisms outperform others in innovation. At the same time, firms in the 'KM moderates' cluster actively use a combination of two knowledge governance mechanisms, and yet their innovation performance is inferior.

\section{DISGUSSION}

Our study aimed to explore the use of knowledge governance mechanisms in the Brazilian context, as well as their effects on firms' innovation performance - individually and combined together in bundles. Our findings indicate that the 
frequency of use of some knowledge governance mechanisms in our sample might be the product of the institutional environment, while for others it is less evidently so. Indeed, the wide use of a knowledge-management-friendly culture is in line with the relational orientation and the high in-group collectivism of the Brazilian culture and the team-oriented and participative leadership often practiced in Brazilian organizations (House et al., 2004). Similarly, the low-level usage of knowledge-focused rewards may be explained by the fear on the part of Brazilian managers that their employees might develop habituality for rewards (Fleury \& Fleury, 1997). However, the widespread use of organizational design appears to run counter to our context-based predictions, rooted in characterizing Brazilian organizations as having excessively hierarchical organizational structures (Amado \& Vinagre, 1991) and being embedded in a national culture with a high degree of power distance, moderately high uncertainty avoidance, and low institutional collectivism (House et al., 2004; Osland et al., 1999). This unexpected finding could be explained by the fact that the past research that led us to our hypothesis regarding the use of organizational design is quite dated, while Brazil's emerging economy is changing very rapidly (Frank et al., 2016). Therefore, this past research may not reflect the contemporary reality of Brazilian organizations, especially in respect of practices, which, unlike values, are easier to change. Indeed, our findings may indicate that managers of Brazilian organizations are actively working to transform their organizational structures to become more flexible and innovative. Finally, the medium-level usage of ICT that supports knowledge processes does not fully fit our predictions. This finding may be explained by several issues or their combination. It may indicate that recent efforts of the Brazilian government to support ICT initiatives have not yet fully paid off, or that these efforts were not sufficiently effective. Taking into account that this government support was aimed at ICT adoption in general, and not knowledge-supportive ICT specifically, our result may also indicate that adoption of knowledge-supportive ICT is not considered to be a priority by Brazilian companies.

In terms of the efficiency of individual knowledge governance mechanisms, two of our findings are particularly interesting. First, to our surprise, we found knowledge-friendly organizational culture to be insignificant for innovation performance - it neither had a direct individual effect, contrary to some previous studies in other countries (Inkinen et al., 2015; Kianto \& Andreeva, 2014), nor was it part of the effective bundle of knowledge governance mechanisms. Taking into account that organizational culture is influenced by national culture and Brazilian culture may be quite supportive of knowledge processes (House et al., 2004; Turner \& Kleiner, 1996), the high usage scores for knowledge-friendly organizational culture in our sample might result from the overall context in which these firms operate rather than from their conscious managerial efforts. Therefore, the inefficiency of this mechanism in Brazilian context could be due to the fact that employees do not perceive it as a distinct signal that their organization is indeed interested in supporting and promoting knowledge-related behaviors. 
Second, we found that knowledge-focused organizational design mechanisms have the strongest direct individual effect on innovation performance. The particular power of these mechanisms in Brazilian context can be explained by the fact that these practices address the structural problems that are acute in many Brazilian organizations: they help to overcome high segmentation and low integration between organizational subsystems (Amado \& Vinagre, 1991; Dávila, North, \& Varvakis, 2016; House et al., 2004). In addition, Strese, Adams, Flatten, and Brettel (2016) pointed out that organizational design decisions that promote risky, innovative behaviors and informal interaction are particularly effective in fostering knowledge management processes in risk-averse national cultures such as the Brazilian one.

At the same time, our cluster analysis indicates that though knowledgefriendly organizational design is used intensively by both 'KM stars' and 'KM moderates', the latter cluster statistically significantly underperforms in innovation compared to the first. In other words, our findings suggest that organizational design might be the necessary but not a sufficient condition for boosting innovation performance. Indeed, what differentiates 'KM stars' from 'KM moderates' is that 'KM stars' use two more knowledge governance mechanisms: knowledgefocused rewards and ICT that support knowledge processes. This suggests that it is the joint use, or bundling, of three practices - rewards, ICT, and organizational design - that makes the difference for innovation performance.

To cross-validate this conclusion, we used an alternative methodology to identify potential interactions between variables, namely moderation analysis (Hayes, 2013). Due to the limitations of our sample size, we had to do this with regression rather than SEM-PLS. The results of our stepwise regression analysis confirm our proposition on the importance of bundling three knowledge governance mechanisms. In the final model, only two predictors of innovation performance remained: organizational design $\left(\beta=0.305, \rho=0.003, \mathrm{f}^{2}=0.088\right)$ and the three-way interaction of rewards, ICT, and organizational design $(\beta=0.259, \rho=0.011$, $\mathrm{f}^{2}=0.063$ ), with the adjusted $\mathrm{R}^{2}$ value for innovation performance being 0.23 . We also explored four-way interaction, including a knowledge-managementfriendly culture, as an alternative interpretation of the 'KM stars' cluster, and this was not statistically significant $(\rho=0.250)$.

In other words, our findings indicate that knowledge-focused rewards and ICT that support knowledge processes positively influence innovation performance only when they are bundled with each other and knowledge-friendly organizational design. The power of this particular bundle may be explained by both generic and Brazil-specific considerations. On the generic side, past research suggests that ICT enhance knowledge processes only when employees are motivated to engage in them (e.g., Andreeva \& Kianto, 2012), and when the 'roads' for technology-enabled knowledge exchanges are created by organizational structure (Grant, 1996). More recently, Foss et al. (2015) have pointed out that knowledge-focused rewards would have a positive effect only when used with other 
practices to ensure employees interpret rewards as informing rather than controlling. In our case, both ICT and organizational design serve this informing purpose well as they merely provide opportunities to engage in knowledge-related processes but do not 'force' employees into them. In the Brazilian context, this most effective bundle can be interpreted as the one that combines generally useful knowledge governance mechanisms with those that are particularly relevant to counteract typical problems of local organizations. Knowledge-focused organizational design practices appear to belong to the latter group, working against historically high segmentation and low integration within Brazilian organizations, and thus enabling other knowledge governance mechanisms to function. In other words, having rewards for engaging in knowledge processes and ICT to support these processes would not be enough to stimulate innovation unless employees developed informal networks across different parts of the organization so that they knew whom to contact using ICT, and the development of such networks is enabled by knowledge-focused organizational design mechanisms. In a similar vein, Commander et al. (2011) found that the effect of ICT adoption on productivity was the strongest in Brazilian firms that simultaneously flattened their organizational structures. The large and intermediate effect sizes of differences between the clusters of 'KM neglects', 'KM stars', and 'KM moderates', compared to small effect sizes of individual knowledge governance mechanisms, also support our suggestion to focus on joint effects of knowledge governance mechanisms rather than individual ones.

Our findings contribute to several discussions in the knowledge management and innovation literature. First, our study informs the discussion on the contextual applicability of different knowledge governance mechanisms around the globe (e.g., Glisby \& Holden, 2003; Sergeeva \& Andreeva, 2016). It illustrates what peculiarities of the institutional context may shape the use and efficiency of various knowledge governance mechanisms, and how they may do so. Recent reviews suggested that one of the reasons for the lack of the context-aware research relates to the challenges of how to describe and analyze the context (Michailova, 2011; Sergeeva \& Andreeva, 2016). In this light, this study provides an example of how the contextual dimension can be meaningfully incorporated into the study of knowledge management issues and therefore methodologically paves the way for more context-aware research in the future. Furthermore, by exploring data from an emerging country, a context that has been under-researched in knowledge management (Inkinen et al., 2015), this study expands the empirical evidence on knowledge governance around the globe. At the same time, understanding the contextual factors that may drive our findings enables us to extend the applicability of our findings beyond Brazil. In particular we propose that in countries with high power distance and low institutional collectivism, which often lead to excessively hierarchical and disconnected organizational structures, the implementation of knowledge-oriented organizational design may be a particularly efficient tool for leveraging innovation. We also propose that in national cultures that appear to 
be naturally supportive of knowledge processes, a knowledge-friendly organizational culture may be less efficient for stimulating innovation due to being perceived as unintentional and thus not signaling managerial intentions clearly enough.

Second, our study adds to the nascent literature exploring potential interactions between different aspects of managing knowledge in organizations (Andreeva et al., 2017; Foss et al., 2015). Our research demonstrates that the joint effects of bundles of knowledge governance mechanisms should be explored in order to understand their impact on organizational outcomes, as direct individual effects do not tell the full story. Interestingly, our findings do not fully support the concerns that having too many knowledge governance mechanisms simultaneously would not be beneficial for an organization (e.g., Andreeva \& Sergeeva, 2016; Minbaeva, 2013). Our study demonstrates that to have a positive effect, the key concern is not the number of mechanisms used but rather jointly applying a certain combination of them. One potential explanation for this may be linked to the nature of the knowledge governance mechanisms discussed in our study: two out of three in our 'KM stars' bundle involve providing opportunities to engage in knowledge sharing and knowledge creation (ICT and organizational design), and only one involves explicitly guiding employees to do so (rewards). In this respect, the main concern about the potential detrimental effects of multiple knowledge governance mechanisms in the literature is grounded in the idea that 'overcontrolling' is detrimental to knowledge-related behaviors (Foss et al., 2015). At the same time, recent research suggests that providing opportunities to engage in knowledge-related behaviors is particularly powerful as it activates the intrinsic motivation crucial for these behaviors (Andreeva \& Sergeeva, 2016). In this light, our 'KM stars' bundle, which is focused on opportunities, may be so efficient because it does not suffer from an overcontrolling effect. Our findings also suggest that the question of which is the most effective bundle of knowledge governance mechanisms may be context-dependent, as the answer needs to include both generally useful knowledge governance mechanisms and those that are particularly relevant to counteract typical organizational challenges in this particular context.

Our study also has some managerial implications. First, it suggests that in the Brazilian context, the most efficient way to boost innovation through knowledge governance mechanisms is to invest efforts in three areas simultaneously: knowledge-focused rewards, knowledge-friendly organizational design, and ICT that support knowledge processes. Our results indicate that focusing on just one or two of these areas would lead to the fruitless use of resources, as the organizational outcomes would not be different from a zero-investment approach. Second, and more broadly of interest for managers around the globe, our study illustrates what contextual factors may impact the performance effects of knowledge governance mechanisms, and how they may do so. This understanding may help managers to find most the balanced and efficient combination of knowledge governance mechanisms for their particular context. 


\section{Limitations and Future Research Avenues}

The limitations of this study offer intriguing avenues for future research. First, we must acknowledge that Brazil is a very heterogeneous country (Caldas, 2006; Story \& Reis, 2014). This study used a sample of firms from Santa Catarina, which is located in the south of the country. This region is described as 'European and prosperous, more hierarchical, less formal, more individualist, and more masculine (achievement-oriented)' than other Brazilian regions (Hofstede, De Hilal, Malvezzi, Tanure, \& Vinken, 2010: 347). Consequently, there may be variations in the efficiency of the knowledge governance mechanisms between different Brazilian regions that we were not able to uncover in this study due to the nature of our sample. Countries are often treated in international research as homogenous entities, simplifying the contextual reality of business in different regions. Future studies might, therefore, explore whether the different knowledge governance mechanisms work similarly or differently across different regions of Brazil - and in the contexts of other emerging economies.

Second, this study was nested within the single-country context and therefore our propositions on how contextual variables affect the efficiency of the various knowledge governance mechanisms could not be properly tested. A comparative study across various countries with different institutional environments and resource availability may enrich our understanding of exactly how these factors matter for the performance of knowledge governance mechanisms. In line with the emerging strategy tripod perspective (e.g., Su, Peng, \& Xie, 2016) future studies could also incorporate characteristics of various industries in order to explore contextual influences at different levels.

Third, our data is of a cross-sectional nature and thus the scope of the conclusions regarding causal relationships between the variables in the model is limited. While the knowledge management literature usually hypothesizes that efforts in managing knowledge lead to an increase in innovative performance, alternative causal explanations may also exist (e.g., Andreeva et al., 2017). For example, companies that are more innovative may invest more in ICT as they have more resources at hand, thanks to increased revenues gained from successful innovation. Some researchers argue that knowledge governance mechanisms have a long-term rather than an immediate effect on performance (Davenport et al., 1998). Such an effect could not be captured in our dataset. Based on these two concerns, future research would benefit from a longitudinal study that tracks the changes in innovation performance after the implementation of certain knowledge governance mechanisms.

Finally, knowledge management is just one of the wide range of antecedents of organizational innovation that have been proposed in the literature (Crossan \& Apaydin, 2010). Focusing on one antecedent naturally leads to relatively low explanatory power of the empirical studies, in the fields where multiple midrange theories compete to explain the phenomenon (Lewin, 2014). To explain innovation performance better, as well as to understand what the contribution of knowledge 
management is compared to other innovation antecedents, especially in the emerging markets contexts, future studies could incorporate multiple antecedents, such as embeddedness in local and global networks (e.g., Figueiredo, 2011; Li, Chen, \& Shapiro, 2010; McDermott et al., 2017) or company's strategic orientations (Frank et al., 2016) and leadership (Crossan \& Apaydin, 2010).

\section{GONGLUSION}

Our findings demonstrate that in the Brazilian context, a knowledge-friendly organizational culture does not have a significant impact on innovation performance, while knowledge-focused organizational design has the strongest individual positive impact on it. At the same time, we find that organizational design is a necessary but not a sufficient condition for ensuring strong innovation performance in Brazilian organizations; the joint application of knowledge-focused rewards, organizational design, and ICT that support knowledge processes is in fact what is required. Our study explores why these knowledge governance mechanisms and their particular combination are so powerful (or not) in this context. In light of this analysis, we conclude that the most efficient ways of managing knowledge in organizations to stimulate their innovativeness may be context-specific, and we would encourage future research to explore this idea further.

\section{NOTES}

We would like to thank the Industry Federation of Santa Catarina (FIESC) for supporting data collection, and CAPES - Brazilian Federal Agency for Support and Evaluation of Graduate Education (PNPD program) for the financial support of the first author. We also greatly appreciate the constructive feedback given on previous drafts of this paper by Management and Organization Review editors Gerald McDermott and Arie Lewin, as well as anonymous reviewers.

[1] Significance levels here and further in the comparison between clusters refer to the Tamhane's

T2 test. Games-Howell test indicated similar results.

\section{APPENDIX I}

\section{Measurement Test Results for the Variables of the Study}

\begin{tabular}{lcc}
\hline Constructs and Indicators & Loadings \\
\hline ICT that supports knowledge processes & 0.78 \\
ICT1 & $\begin{array}{l}\text { Our organization uses technologies (e.g., Intranet, Internet, e-mail, and } \\
\text { e-learning) to facilitate employees sharing new ideas/knowledge with each } \\
\text { other }\end{array}$ & \\
KCT2 & $\begin{array}{l}\text { KM systems and tools in our organization are widely accepted, monitored, and } \\
\text { updated. }\end{array}$ & 0.83 \\
ICT3 & $\begin{array}{l}\text { Our organization's ICT is capable of supporting management decisions and } \\
\text { knowledge work }\end{array}$ & 0.87 \\
\hline
\end{tabular}


Continued

Constructs and Indicators

Loadings

ICT4 Our organization's ICT architecture is capable of sharing data and informa-

0.72

tion, knowledge, and expertise with all stakeholders in the organization's extended value chain.

ICT5 Our organization's current ICT systems are sufficient to support the daily work

Knowledge-focused organisational design

OD1 People from different parts of our organization interact informally with each $\quad 0.70$ other in a frequent manner

OD2 In our organization, open dialogs are common among/between employees and 0.72 manager

OD3 In our projects, our organization uses teams consisting of people with skills and 0.84 expertise from diverse fields

OD4 In our organization, we frequently use cross-functional teams and projects $\quad 0.79$

OD5 In our organization, we have purposeful overlap of functional responsibilities $\quad 0.68$

\section{Knowledge-focused rewards}

REW1 Our organization specifically rewards knowledge sharing with monetary incentives.

REW2 Our organization specifically rewards knowledge sharing with non-monetary $\quad 0.88$ incentives.

REW3 Our organization specifically rewards knowledge creation with monetary incentives.

REW4 Our organization specifically rewards knowledge creation with non-monetary incentives.

Knowledge-friendly organisational culture

$\begin{array}{ll}\text { OC1 } 1 & \text { Openness and trust are valued in our organization. }\end{array}$

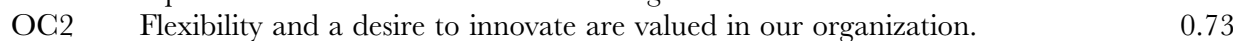

OC3 Employees who take initiative of their own learning are highly valued in our $\quad 0.80$

OC4 Willingness to share lessons learned is valued in our organization. 0.82

OC5 In our organization, lessons learned both successful and unsuccessful are con- $\quad 0.87$ sidered valuable.

OC6 In our organization various units are encouraged to collaborate with each other.

\section{Innovation Performance}

IP1 Compared to its competitors, during the last year our company successfully managed to create innovations in new products or services for customers.

IP2 Compared to its competitors, during the last year our company successfully managed to create innovations in new production methods and processes.

IP3 Compared to its competitors, during the last year our company successfully managed to create innovations in new management practices.

IP4 Compared to its competitors, during the last year our company successfully managed to create innovations in new marketing practices.

IP5 Compared to its competitors, during the last year our company successfully managed to create innovations in new business models.

\section{REFERENGES}

Alavi, M., Kayworth, T. R., \& Leidner, D. E. 2006. An empirical examination of the influence of organizational culture on knowledge management practices. Journal of Management Information Systems, 22(3): 91-224.

Alegre, J., Sengupta, K., \& Lapiedra, R. 2013. Knowledge management and innovation performance in a high-tech SMEs industry. International Small Business Journal, 31(4): 454-470. 
Amado, G., \& Vinagre Brasil, H. 1991. Organizational behaviors and cultural context: The Brazilian 'Jeitinho'. International Studies of Management \& Organization, 21(3): 38-61.

Andreeva, T., \& Ikhilchik, I. 2011. Applicability of the SECI model of knowledge creation in Russian cultural context: Theoretical analysis. Knozeledge and Process Management, 18(1): 56-66.

Andreeva, T., \& Kianto, A. 2012. Does knowledge management really matter? Linking knowledge management practices, competitiveness and economic performance. Joumal of Knozeledge Management, 16(4): 617-636.

Andreeva, T., \& Sergeeva, A. 2016. The more the better... Or is it? The contradictory effects of HR practices on knowledge sharing motivation and behavior. Human Resource Management Journal, 26(2): 151-171.

Andreeva, T., Vanhala, M., Sergeeva, A., Ritala, P., \& Kianto, A. 2017. When the fit between HR practices backfires: Exploring the interaction effects between rewards for and appraisal of knowledge behaviours on innovation. Human Resource Management Journal, 27(2): 209-227.

Ardichvili, A., Maurer, M., Li, W., Wentling, T., \& Stuedemann, R. 2006. Cultural influences on knowledge sharing through online communities of practice. Journal of Knozeledge Management, 10(1): 94-107.

Armstrong, J. S., \& Overton, T. S. 1977. Estimating nonresponse bias in mail surveys. Journal of Marketing Research, 14(3): 396-402.

Barradas, J. S., \& Campos Filho, L. A. N. 2010. Knowledge management trends in Brazil content analysis in the opinion of Brazilians' specialists. Perspectivas em Ciência da Informação, 15(3): 131-154.

Barros, H. M. 2015. Exploring the use of patents in a weak institutional environment: The effects of innovation partnerships, firm ownership, and new management practices. Technovation, 45: 63-77.

Barros, H. M., \& Lazzarini, S. G. 2012. Do organizational incentives spur innovation? $\boldsymbol{B A R}$ Brazilian Administration Revieze, 9(3): 308-328.

Bruton, G. D., Dess, G. G., \& Janney, J. J. 2007. Knowledge management in technology-focused firms in emerging economies: Caveats on capabilities, networks, and real options. Asia Pacific Journal of Management, 24(2): 115-130.

Buenechea-Elberdin, M., Kianto, A., \& Sáenz, J. 2018. Intellectual capital drivers of product and managerial innovation in high-tech and low-tech firms. R\&D Management 48(3): 290-307.

Caldas, M. P. 2006. Conceptualizing Brazilian multiple and fluid cultural profiles. Management Research: Joumal of the Iberoamerican Academy of Management, 4(3): 169-180.

Chandy, R. K., \& Tellis, G. J. 2000. The incumbent's curse? Incumbency, size, and radical product innovation. Journal of Marketing, 64(3): 1-17.

Cohen, J. 1988. Statistical pozer analysis for the behavioral sciences. Hillsdale, NJ: Erlbaum.

Commander, S., Harrison, R., \& Menezes-Filho, N. 2011. ICT and productivity in developing countries: New firm-level evidence from Brazil and India. Revieze of Economics and Statistics, 93(2): 528-541.

Connelly, B. L., Certo, S. T., Ireland, R. D., \& Reutzel, G. R. 2011. Signaling theory: A review and assessment. Journal of Management, 37(1): 39-67.

Creswell, J. W. 2013. Research design: Qualitative, quantitative, and mixed methods approaches. Thousand Oaks, CA: Sage Publications.

Crossan, M. M., \& Apaydin, M. 2010. A multi-dimensional framework of organizational innovation: A systematic review of the literature. Journal of Management Studies, 47(6): 1154-1191.

Darroch, J. 2005. Knowledge management, innovation and firm performance. Journal of Knozledge Management, 9(3): 101-115.

Davenport, T. H., De Long, D. W., \& Beers, M. C. 1998. Successful knowledge management projects. Sloan Management Revieze, 39(2): 43-57.

Dávila, G. A., North, K., \& Varvakis, G. 2016. How Brazilian textile enterprises learn to grow. In K. North \& G. Varvakis (Eds.), Competitive strategies for small and medium enterprises: 241-254. Switzerland: Springer International Publishing.

De Long, D. W., \& Fahey, L. 2000. Diagnosing cultural barriers to knowledge management. Academy of Management Perspectives, 14(4): 113-127.

Dominguez Gonzalez, R. V., \& Martins, M. F. 2014. Mapping the organizational factors that support knowledge management in the Brazilian automotive industry. Journal of Knozledge Management, 18(1): 152-176.

Ellonen, R., Blomqvist, K., \& Puumalainen, K. 2008. The role of trust in organisational innovativeness. European Journal of Innovation Management, 1 1(2): 160-181. 
FIESC. 2017. Santa Catarina em Dados 2017. Industry Federation of Santa Catarina - FIESC, Florianópolis.

Figueiredo, P. N. 2005. Acumulação tecnológica e inovação industrial: Conceitos, mensuração e evidências no Brasil. São Paulo em Perspectiva, 19(1): 54-69.

Figueiredo, P. N. 2011. The role of dual embeddedness in the innovative performance of MNE subsidiaries: Evidence from Brazil. Journal of Management Studies, 48(2): 417-440.

Fischer, A. L., \& de Albuquerque, L. G. 2005. Trends of the human resources management model in Brazilian companies: A forecast according to opinion leaders from the area. International Journal of Human Resource Management, 16(7): 1211-1227.

Fischer, R., Smith, P. B., Richey, B., Ferreira, M. C., Assmar, E. M. L., Maes, J., \& Stumpf, S. 2007. How do organizations allocate rewards? The predictive validity of national values, economic and organizational factors across six nations. Journal of Cross-Cultural Psychology, 38(1): 3-18.

Fleury, A., \& Fleury, M. T. L. 1997. Aprendizagem e inovação organizacional: As experiências de Japão, Coréia e Brasil. São Paulo: Atlas.

Fleury, A., Fleury, M. T. L., \& Borini, F. M. 2013. The Brazilian multinationals' approaches to innovation. Journal of International Management, 19(3): 260-275.

Fornell, C., \& Larcker, D. F. 1981. Evaluating structural equation models with unobservable variables and measurement error. Journal of Marketing Research, 18(1): 39-50.

Foss, N. J., \& Michailova, S. 2009. Knozledge governance: Processes and perspectives. New York: Oxford University Press.

Foss, N. J., Husted, K., \& Michailova, S. 2010. Governing knowledge sharing in organizations: Levels of analysis, governance mechanisms, and research directions. Journal of Management Studies, 47(3): 455-482.

Foss, N.J., Pedersen, T., Reinholt, M., \& Stea, D. 2015. Why complementary HRM practices impact performance: The case of rewards, job design, and work climate in a knowledge-sharing context. Human Resource Management, 54(6): 955-976.

Frank, A. G., Cortimiglia, M. N., Ribeiro, J. L. D., \& de Oliveira, L. S. 2016. The effect of innovation activities on innovation outputs in the Brazilian industry: Market-orientation vs technology acquisition strategies. Research Policy, 45(3): 577-592.

Glisby, M., \& Holden, N. 2003. Contextual constraints in knowledge management theory: The cultural embeddedness of Nonaka's knowledge-creating company. Knozeledge and Process Management, 10(1): 29-36.

Grant, R. M. 1996. Toward a knowledge-based theory of the firm. Strategic Management Journal, 17(S2): 109-122.

Gruber, M., Heinemann, F., Brettel, M., \& Hungeling, S. 2010. Configurations of resources and capabilities and their performance implications: An exploratory study on technology ventures. Strategic Management Journal, 31(12): 1337-1356.

Hair, J. F., Black, W. G., Babin, B. J., Anderson, R. E., \& Tatham, R. L. 2006. Multivariate data analysis. Upper Saddle River, NJ: Pearson Prentice Hall.

Harkness, J. A. 2003. Questionnaire translation. Cross-cultural Survey Methods, 1: 35-56.

Hayes, A. F. 2013. Introduction to mediation, moderation and conditional process analysis: A regression based approach. New York: The Guilford Press.

Hedges, L., \& Olkin, I. 1985. Statistical methods for meta-analysis. New York: Academic Press.

Henseler, J., Hubona, G., \& Ray, P. A. 2016. Using PLS path modeling in new technology research: Updated guidelines. Industrial Management \& Data Systems, 116(1): 2-20.

Hofstede, G., De Hilal, A. V. G., Malvezzi, S., Tanure, B., \& Vinken, H. 2010. Comparing regional cultures within a country: Lessons from Brazil. Journal of Cross-Cultural Psychology, 41(3): 336-352.

House, R. J., Hanges, P. J., Javidan, M., Dorfman, P. W., \& Gupta, V. 2004. Culture, leadership, and organizations: The GLOBE study of 62 societies. Thousand Oaks, CA: Sage Publications.

Inkinen, H. T., Kianto, A., \& Vanhala, M. 2015. Knowledge management practices and innovation performance in Finland. Baltic Journal of Management, 10(4): 432-455.

Jennings, D. F., \& Young, D. M. 1990. An empirical comparison between objective and subjective measures of the product innovation domain of corporate entrepreneurship. Entrepreneurship Theory and Practice, 15(1): 53-66. 
Ketchen, D., \& Shook, C. 1996. The application of cluster analysis in strategic management research: An analysis and critique. Strategic Management Journal, 17(6): 441-458.

Kianto, A., \& Andreeva, T. 2014. Knowledge management practices and results in service-oriented versus product-oriented companies. Knozeledge and Process Management, 21(4): 221-230.

Kock, N. 2015. Common method bias in PLS-SEM: A full collinearity assessment approach. International Joumal of e-Collaboration (IJeC), 11(4): 1-10.

Lakshman, C., \& Parente, R. C. 2008. Supplier-focused knowledge management in the automobile industry and its implications for product performance. Journal of Management Studies, 45(2), 317-342.

Lee Park, C., Fracarolli Nunes, M., Muratbekova-Touron, M., \& Moatti, V. 2018. The duality of the Brazilian jeitinho: An empirical investigation and conceptual framework. Critical Perspectives on International Business, 14(4): $404-425$.

Lenartowicz, T., \& Johnson, J. 2003. A cross-national assessment of the values of Latin America managers: Contrasting hues or shades of gray? Journal of International Business Studies, 34(3): 266-281.

Lenhard, W., \& Lenhard, A. 2016. Calculation of effect sizes. Bibergau: Psychometrica. Available online at: https://www.psychometrica.de/effect_size.html

Lewin, A. Y. 2014. The peer-review process: The good, the bad, the ugly, and the extraordinary. Management and Organization Review, 10(2): 167-173.

Li, J., Chen, D., \& Shapiro, D. 2010. Product innovations in emerging economies: The role of foreign knowledge access channels and internal efforts in Chinese firms. Management and Organization Revieze, 6(2): 243-266.

Liang, H., Saraf, N., Hu, Q., \& Xue, Y. 2007. Assimilation of enterprise systems: The effect of institutional pressures and the mediating role of top management. MIS quarterly, 31(1): 59-87.

Lowry, P. B., \& Gaskin, J. 2014. Partial least squares (PLS) structural equation modeling (SEM) for building and testing behavioral causal theory: When to choose it and how to use it. IEEE Transactions on Professional Communication, 57(2): 123-146.

Lu, Y., Tsang, E. W., \& Peng, M. W. 2008. Knowledge management and innovation strategy in the Asia Pacific: Toward an institution-based view. Asia Pacific Joumal of Management, 25(3): 361-374.

Manhães, M., \& Dávila, G. A. 2016. The innovation triple challenge: A creativity check for SMEs. In K. North \& G. Varvakis (Eds.), Competitive strategies for small and medium enterprises: 77-92. Switzerland: Springer International Publishing.

May, R. C., \& Stewart, W. H. 2013. Building theory with BRICs: Russia's contribution to knowledge sharing theory. Critical Perspectives on International Business, 9(1-2): 147-172.

McDermott, G. A., \& Pietrobelli, C. 2017. Walking before you can run: The knowledge, networks, and institutions for emerging market SMEs. In T. Pedersen, T. M. Devinney, L. Tihanyi, \& A. Camuffo (Eds.), Breaking up the global value chain: Opportunities and consequences: 311-332. Bingley, UK: Emerald Publishing Limited.

Meyer, A., Tsui, A., \& Hinings, C. 1993. Configurational approaches to organizational analysis. Academy of Management Journal, 36(6): 1175-1195.

Meyer, K. 2015. Context in management research in emerging economies. Management and Organization Revieze, 11(3): 369-377.

Michailova, S. 2011. Contextualizing in international business research: Why do we need more of it and how can we be better at it? Scandinavian Journal of Management, 27(1): 129-139.

Michailova, S., \& Hutchings, K. 2006. National cultural influences on knowledge sharing: A comparison of China and Russia. Journal of Management Studies, 43(3): 383-405.

Michailova, S., \& Sidorova, E. 2010. Knowledge management in transition economies: Selected key issues and possible research avenues. Organizations \& Markets in Emerging Economies, $1(1): 68-81$.

Miles, R. E., Snow, C. S., Mathews, J. A., Miles, G., \& Coleman, H. J., Jr. 1997. Organizing in the knowledge age: Anticipating the cellular form. Academy of Management Executive, 11 (4): $7-20$.

Minbaeva, D. 2013. Strategic HRM in building micro-foundations of organizational knowledgebased performance. Human Resource Management Revieze, 23(4): 378-390.

Moder, K. 2010. Alternatives to F-Test in One Way ANOVA in case of heterogeneity of variances (a simulation study). Psychological Test and Assessment Modeling, 52(4): 343-353.

Oliva, F. L. 2014, Knowledge management barriers, practices and maturity model. Journal of Knozledge Management, 18(6): 1053-1074. 
Osland, J. S., De Franco, S., \& Osland, A. 1999. Organizational implications of Latin American culture: Lessons for the expatriate manager. Journal of Management Inquiry, 8(2): 219 234.

Podsakoff, P. M., MacKenzie, S. B., \& Podsakoff, N. P. 2012. Sources of method bias in social science research and recommendations on how to control it. Annual revieze of psychology, 63: 539569.

Ringle, C. M., Sarstedt, M., \& Straub, D. W. 2012. Editor's comments: A critical look at the use of PLS-SEM in MIS quarterly. MIS Quarterly, 36(1): iii-xiv.

Rodrigues, S., Duarte, R., \& Carrieri, A. 2012. Indigenous or imported knowledge in Brazilian management studies: A quest for legitimacy? Management and Organization Revieze, 8(1): 211-232.

Rodríguez, A., Dahlman, G., \& Salmi, J. 2008. Knozeledge and innovation for competitiveness in Brazil. Washington, DC: The World Bank.

SEBRAE. 2017. Anuário do trabalho na micro e pequena empresa 2015. Brazilian Service of Support for Micro and Small Enterprises - SEBRAE, São Paulo. https://m.sebrae.com.br/ Sebrae/Portal\%20Sebrae/Anexos/anu\%C3\%Alrio\%20do\%20trabalho\%202015.pdf

Sergeeva, A., \& Andreeva, T. 2016. Knowledge sharing research: Bringing context back in. Journal of Management Inquiry, 25(3): 240-261.

Song, M., Droge, C., Hanvanich, S., \& Calantone, R. 2005. Marketing and technology resource complementarity: An analysis of their interaction effect in two environmental contexts. Strategic Management Journal, 26(3): 259-276.

Sparkman, T. E. 2015. The factors and conditions for national human resource development in Brazil. European Journal of Training and Development, 39(8): 666-680.

Stone, M. 1974. Cross-validatory choice and assessment of statistical predictions. Journal of the Royal Statistical Society. Series B (Methodological), 36(2): 111-147.

Story, J., \& Reis, G. G. 2014. Managing the Brazilian way: Adaptation and integration. In B. Gehrke \& M.-T. Claes (Eds.), Global leadership practices: A cross-cultural management perspective: 203-21. London: Red Globe Press.

Strese, S., Adams, D. R., Flatten, T. C., \& Brettel, M. 2016. Corporate culture and absorptive capacity: The moderating role of national culture dimensions on innovation management. International Business Revieze, 25(5): 1149-1168.

Su, Z., Peng, M. W., \& Xie, E. 2016. A strategy tripod perspective on knowledge creation capability. British Journal of Management, 27(1): 58-76.

Thürer, M., Godinho Filho, M., Stevenson, M., \& Fredendall, L. D. 2013. Competitive priorities of small manufacturers in Brazil. Industrial Management \& Data Systems, 113(6): 856-874.

Turner, W., \& Kleiner, B. H. 1996. What managers must know to conduct business in Brazil. Management Research Nezes, 19(11): 58-63.

Wan, W. P. 2005. Country resource environment, firm capabilities, and corporate diversification strategies. Joumal of Management Studies, 42(1): 161-182.

Weerawardena, J. 2003. Exploring the role of market learning capability in competitive strategy. European Journal of Marketing, 37(3): 407-429.

Whetten, D. 2009. An examination of the interface between context and theory applied to the study of Chinese organizations. Management and Organization Revieze, 5(1): 29-56.

Youndt, M. A., Subramaniam, M., Snell, S. A. 2004. Intellectual capital profiles: An examination of investments and returns. Journal of Management Studies, 41(2): 335-361.

Zack, M. H. 1999. Managing codified knowledge. Sloan Management Revieze, 40(4): 45-58.

Guillermo Antonio Dávila (davila.guillermo@gmail.com) is a Senior Researcher in the Department of Knowledge Engineering and Management at Federal University of Santa Catarina - UFSC, Florianopolis, Brazil. His current research covers knowledge management, innovation management, and technology transfer in an international context with special reference to Latin American countries. He has been working for more than 10 years in sectors such as insurance, banking, FDI and IT services. His academic work has been published in international journals and textbooks. 
Tatiana Andreeva (tatiana.andreeva@nuim.ie) is a Senior Lecturer in Management and Organizational Behavior and Research Director at the School of Business at the Maynooth University, Ireland. She holds a PhD in Human Resource Management from St. Petersburg University, Russia. Her current research addresses the challenges of managing knowledge in organizations, with a particular focus on the micro-foundations of knowledge processes and peculiarities of the contexts in which they evolve. Her work has been published in leading journals such as Human Resource Management Fournal, Human Resource Management, and Journal of Management Inquiry, amongst others.

Gregório Varvakis (g.varvakis@ufsc.br) is a professor and Head of the Department of Knowledge Engineering and Management at Federal University of Santa Catarina - UFSC, Florianopolis, Brazil. He holds a $\mathrm{PhD}$ in Manufacturing Engineering from Loughborough University, England. He has been a consultant at McKINSEY LTDA. His teaching courses and research covers Knowledge and service management with special attention to productivity improvement. He was co-leader of the Dynamic SME project.

Manuscript received: May 2, 2017

Final version accepted: November 11, 2018 (number of revisions - 2)

Accepted by: Deputy Editor Gerald McDermott 